Article

\title{
Readiness of Enterprises in Czech Republic to Implement Industry 4.0: Index of Industry 4.0
}

\author{
Jaroslav Vrchota *(D) and Martin Pech $\mathbb{D}$ \\ Department of Management, Faculty of Economics, University of South Bohemia in Ceske Budejovice, \\ Studentska 13, 37005 Ceske Budejovice, Czech Republic; mpechac@ef.jcu.cz \\ * Correspondence: vrchota@ef.jcu.cz
}

Received: 14 November 2019; Accepted: 6 December 2019; Published: 10 December 2019

\begin{abstract}
Industry 4.0 includes digital process transformation, information technology (IT) development, mobile devices, learning software, automation, and robotics, as well as intelligent sensors to collect large datasets, store, analyze, and use them in business, including simulation, virtual reality, and digital twins. The aim of the paper is to characterize the readiness of the enterprise to use Industry 4.0. In the research, a questionnaire survey was carried out on a sample of 276 enterprises mainly from the manufacturing industry. Using explorative factor analysis, the index of Industry 4.0 (VPi4) was designed to determine the level of Industry 4.0 implementation in the enterprises. The results were further verified by a statistical analysis, using Mann-Whitney test and correlation coefficients. The results indicate that the VPi4 index was consistent in terms of distribution when comparing the results on the verification sample. Its results correlate with the subjective perception of the enterprises, and different levels of the index reflect the difference in technological intensity of the industry. The VPi4 index enables the enterprises to determine their own level of current state of readiness for Industry 4.0, to better prioritize business development. The proposed solution categorizes Industry 4.0 components into a useful theoretical framework. Further research offers the possibility of applying the index in other sectors, its relation to the size of enterprises, and updating with respect to new trends in information technology.
\end{abstract}

Keywords: Industry 4.0; index; smart; intensity of technology; manufacturing; implementation

\section{Introduction}

Industry 4.0 is a platform combining a variety of advanced modern technologies to meet today's challenges. Industry 4.0 elements are increasingly emerging as one of the main strategic management goals in recent years. The use of new technologies raises the need for long-term and strategic investments, intended to increase the competitiveness of the enterprises in the future. Most of the enterprises are already implementing smart technologies and smart processes. Some of the enterprises indicate their experience with such technologies practically. They use the new technologies at least partially. It means that they successfully completed the implementation, and they are now looking for the added value that these technologies offer. However, their use is still partial, used to deal with certain issues and probably without the overall interdependence of all the systems.

Finally, outside this area, there is a small group of innovators, looking for new developments and looking for ways to integrate them into their well-functioning organizations. They have in common mastering the basic and higher levels of Industry 4.0 brought by the Fourth Industrial Revolution, now preparing for further global changes brought about by advances in artificial intelligence, digitalization, computer science, robotics, complexity, and network theory. They include the enterprises that are at the heart of these changes, drawing their energy and position from these processes. 
The current challenges of Industry 4.0 force managers to discuss whether they are prepared for such changes. They often wonder what the situation is in their own organizations and then which technology they should invest into in the near future.

Lower absorption capacity of the enterprises is related to the issue of resource constraints. Right now, the managements of a number of enterprises consider the future strategy and the steps to be taken to be competitive in the future. For this reason, this paper discusses how to assess and analyze the current state of business in the context of Industry 4.0. Based on the research, the authors suggest a methodology, with an index for easy evaluation of the preparedness of the enterprise for the future.

The structure of this paper is organized as follows: Section 2 defines the theory as used in the paper; Section 3 describes the methodology and methods used; Section 4 summarizes the most important results, including the evaluation of the hypotheses; Section 5 discusses the results with other authors; finally, Section 6 summarizes the most important conclusions of the research.

\section{Theoretical Background}

The cornerstone of Industry 4.0 is based on machines, equipment, logistics, and humans who are connected to each other to exchange data, process data, and make decisions, appropriately coordinating the ever-present machines [1]. Industry 4.0 is characterized primarily by digitization, robotics, and artificial intelligence. Kelkar [2] emphasized that $79 \%$ of the manufacturing enterprises (any size) perceive Industry 4.0 as very important for their development (research was conducted in 227 enterprises). Similarly, in Computer Science Corp (2015), 63\% of United States (US) manufacturing companies (900 in the sample) identified Industry 4.0 as necessary for their further development. Consistent with these findings, there is a study of 235 German enterprises carried out by PricewaterhouseCoopers [3], reporting that the enterprises plan to increase digitization between $24 \%$ and $86 \%$ in the next five years. Dörfler [4], who stated that $94 \%$ of companies perceive digitization as important for their development, reported the highest percentage. This research was carried out regardless of the size and area of business using a sample of 1849 German enterprises [5].

The subsequent sub-sections describe theoretic background of the main technologies and processes which are necessary to create future intelligent factories and enterprises based on the conception of Industry 4.0 .

\subsection{Use of Sensors}

Sensors are sources of information for the control system (computer, brain) and technical devices, which measure certain physical and technical quantities and convert them into a signal that is remotely transmitted and further processed. These are various global positioning system (GPS) sensors, cameras, and microphones, forming the digital nervous system. These devices acquire information on position, distance, motion, speed, displacement, temperature, drought, humidity, sound, vibration, gases, chemicals, flow, strength, load, pressure, level, electricity, acceleration, tilt, light, etc. The use of sensors in smart factories has many facets, as discussed by many authors [6-8]. To make full use of the sensors, the availability of efficient and affordable sensor networks (such as radio frequency identification, RFID) is a prerequisite [9]. Based on this, intelligent objects and devices are created, enabling real-time communication between computers, work resources, and application systems. Together, this technological development provides the basis for the introduction of new production processes and business models in smart factories [10]. As they are able to retrieve and process data, they can check certain tasks and communicate with people through an interface [6]. The importance of sensors for Industry 4.0 is also illustrated by the fact that, as mentioned by Reference [7], by 2020, nearly 20.8 billion devices will be connected and RFID will be fully utilized. Such a shift will have an impact on most industrial sectors and, in particular, manufacturing industries. RFID technology is used to identify various objects in warehouses, production halls, logistics companies, distribution centers, retail outlets, and disposal/recycling stages [11]. Analysis of monitored activities will be used for fault detection and predictive maintenance [12]. Based on the information gathered and also using 
machine-to-machine (M2M) communication, the resources will be remotely controlled to improve industrial processes [13].

\subsection{Data Collection and Analysis}

The process of data collection process includes retrieving, searching, selecting, and generating. As more and more business activities are digitized, new data sources arise, and the equipment to process these data becomes increasingly cheaper; we are entering a new era [14]. The volume of stored data is growing four times faster than the world economy, and computing power is increasing nine times faster. Interestingly, in 2000, only one-quarter of the world's information volume was stored in digital form; today, the figure is close to $95 \%$ [15]. The creation of large volumes of data is supported by digitization, aiming to convert all possible information and media-text, sounds, photos, videos, and instrument and sensor data-to the natural language of computers. Big data is a versatile term for any collection of datasets that are very large and complex. Big data are quantified in petabytes $\left(10^{15}\right)$, as it is not possible to receive, store, secure, process, and visualize them with common hardware and software in a reasonable time [15].

Big data are defined as a cultural, technological, and scientific phenomenon that rests on interplay [16] of technology and analysis. Laney $[17,18]$ defined big data through three characteristics: volume, variety, and velocity. The Gartner company introduced the term big data. Gantz and Reinsel [19] complemented the big data characteristics with a fourth Vs value. Reference [20] classified big data through a data life cycle that includes data, process, and management activities. Ge, Bangui, and Buhn [21] classified big data in eight areas: healthcare, automation, transport, energy, smart cities, agriculture, industry, and military.

Data analysis can be expressed through different terms such as data mining, clustering, classification, analytics, aggregation, annotation, combining, extraction, evaluation, and filtering. Data analysis is performed either directly through a variety of cloud computing services (PaaS platform as a Service; SaaS - Software as a Service), or in a conventional way on the user's end computers [19]. The main advantage of cloud services is effective integration with other applications, scalability, performance, multitasking, and configurability [22]. According to Tsai et al. [23], data analysis methods have the following limitations for big data usage: centrality and unscalability, dynamics (inability to analyze data on the fly), and data structure format (data inconsistency).

\subsection{Information Technology (IT) Infrastructure and Mobile Terminals}

In particular, Industry 4.0 includes a radical shift in how IT infrastructure works, defined as the overall transformation of the manufacturing industry through the introduction of digitization and the internet.

These transformations mean a revolutionary improvement in the design and manufacturing processes, operations, and services of manufacturing products and systems. Tjahjono [24] defines Industry 4.0 requirements for IT infrastructure in terms of device automation, auto-driving, increased need for reality, an extremely large number of monitored and managed devices, and process automation.

The enterprises using the Internet of things (IoT) cannot rely solely on wireless networks such as WiFi, ZigBee, and low-power wide-area network (LPWAN) for their future critical related systems [25]. They demand more and more functionality now unavailable according to Rao and Prasad [26], particularly including very low latency, very high reliability, and very high bandwidth and bit rate.

Many of the current network technologies (2G, 3G, 4G - 2nd, 3rd, 4th Generation of mobile telecommunications technology, NFC - Near Field Communication, ANT - Adaptive Network Topology, Bluetooth, GSM - Global System for Mobile communication, WMAX — Woldwide Interoperability for Microwave Access, etc.) are not really good for the future. Future flexibility is offered by the 5G (5th generation of mobile telecommunications technology) standardization as recommended by Sriganesh [26] for infrastructure. Future infrastructure will lead to vertical and horizontal network connectivity and the use of the industrial internet concept. For example, General 
Electric's practice Leber [27] described it as connecting industrial sensors and drives to local processing and the internet. Furthermore, links with other important industrial networks can independently create value. The main difference between consumer/social internet and industrial internet lies in the value created. For consumer/social websites, most of the value is created from ads [28].

\subsection{Cloud Storage}

Data storage includes recording, transportation, replication, compression, cleaning, indexing, stream processing, integration, and transformation of data. Given the increase in data volume (big data), the main question is how to store all data and where. Data warehouses and centers are the most often used. A data warehouse (DW) is an integrated collection of subject-oriented decision support data [29]. Data warehousing (DW) is a specific type of information system and should enable the acquisition of business data, its transformation into appropriate strategic business information, and subsequent storage of data in a format that facilitates business analysis [30]. The cloud is currently the hardware and software solution of the data center providing the services [31]. The cloud is a parallel and distributed computing system consisting of a collection of interconnected and virtualized computers that are dynamically delivered and presented as one or more unified computing resources based on service level agreements negotiated between a service provider and a customer [32]. Such resources are dynamically transformed to adapt to variable load, enabling the optimal use of resources [33]. Clouds are hardware services offering computing, networking, and storage capacity [34]. Mostly, clouds are operated on a cloud deployment models basis [35]: public cloud, private cloud, hybrid cloud, and community cloud [36-38]. The cloud inherently includes the concept of cloud computing, based on the provision of services or programs stored on servers and the internet. Cloud computing distinguishes three types of distribution models [22]: IaaS (infrastructure as a service), PaaS (platform as a service), and SaaS (software as a service). For the purposes of data storage, there are IaaS services, i.e., the use of virtualization, providing only infrastructure and hardware. Block chain technology [39] is emerging significantly in the architecture of the internet and is pushing out the standard model of client-server architectures. The point is that individual transactions between different entities are transparent to everyone, but no one other than the two entities that took the action can influence and change this record. Block chains remove the third-party distribution of information flow [40]. Block chain is basically a data structure that is used to create a digital transaction ledger that is not stored by a single provider but is shared across a distributed network of computers. Block chain is, therefore, a special type of distributed decentralized database in which records are stored.

\subsection{Information Systems and Learning Software}

The implementation of Industry 4.0 uses the concept of an automation pyramid in connection with information technology. The pyramid is closely related to the vertical integration of information systems in an enterprise. Typical solutions and technologies in this vertical integration include data acquisition sensors: programmable logic controllers (PLC) that control production processes and take control levels, supervisory control and data acquisition (SCADA), which allows managing different levels of support processes and supervision, manufacturing execution systems (MES) controlling production processes, and intelligent enterprise resource planning (ERP) management for the enterprise level, the highest level in this hierarchical image [41-43]. ERP supports enterprise-wide planning such as business planning, supply chain management, sales and distribution, accounting, human resources management, and the like. These are usually commercially available solutions.

German SAP SE (Systems, Aplications \& Product in Data Processing Service) is currently the leading SAP solution. In traditional ERP tools, the decision-making process is centralized at the highest level; most available ERP solutions do not support rapid adaptation in production planning due to unplanned events. MES supports reporting, scheduling, dispatching, product tracking, maintenance, performance analysis, workforce tracking, resource allocation, and more [44]. Most systems work with their own way of storing data and, often, with their own data format. The use of a production system 
(MES) as a central database is a solution to such an issue [45]. In the future, a decentralized IT solution in smart factories might be used. In order to give the employees the right data in time, a support system is needed [46]. As Haddara [47] noted, it is the right time to check the readiness of ERP systems to meet the demands of the factories of the future. SAP developed its predictive maintenance module, based on firm integration of robots, machines (to be maintained), and ERP. Predictive maintenance is based both on the integration of data from ERP data sensors and the predictive algorithms.

Learning software includes pattern and machine learning (ML), which embodies some of the aspects of the human mind that allow us to deal with an extremely complex solution to the problem with the speed overcoming even the fastest computers [48]. Wen et al. [49] reported the most commonly used techniques: case-based reasoning (CBR) [50], artificial neural networks (ANN) decision trees (DT) [51], Bayesian networks (BN) [52], support vector regression (SVR) [53], genetic algorithms (GA) [54], genetic programming (GP) [55,56], association rules (AR) [57], rule induction (RI) [58], and fuzzy algorithms [59].

\subsection{Robots}

Production process automation began in the 1960s with the introduction of industrial robots into the automotive manufacturing process. The automation of production systems by the introduction of industrial robots is an ongoing process and is now in line with the evolution of information technology [7]. Industrial robots, ranked in Industry 4.0, are divided into the following two types [60]:

- The machines that help and facilitate the handling of physical objects by reducing human effort without deducting sensitivity and accuracy;

- The machines that learn from their errors and are, therefore, able to gradually function better and manage their own development.

The area of collaborative robots was extensively explored, but it is necessary to define precisely what type of robot can be specified as cooperative. Even with many products available [61] and after the completion of many research projects [62], the definition of a collaborative robot remains unclear. Based on SICK AG (sensor intelligence), there are three types of human-robot interaction [63]: coexistence, cooperation, and collaboration. Robots play an important role in the modern manufacturing industry. Since 2004, the number of multipurpose industrial robots developed by enterprises in the 4.0 sector in Europe almost doubled [15]. The number of installed industrial robots is calculated per 10,000 employees in the manufacturing industry. The highest robot densities in 2017 according to the International Federation of Robotics [62] were found in the Republic of Korea (710), Singapore (658), and Germany (322). The world average was 85 robots per 10,000 employees; however, during the period 2013-2017, global sales of industrial robots increased by $114 \%$. The use of robots is expanding to include a variety of functions: production, logistics, office management (for document distribution), maintenance, and repair of manufacturing defects [64]. An autonomous robot is a robotic device that works independently (it is not controlled in real time by a human, but by a program). In the future, they will be based on artificial intelligence and they will be capable of learning [65].

\subsection{M2M Communication}

Digital production includes a wide range of applied sciences. Studies in these fields attract a lot of effort both in academia and in industry, especially in connection with machine connectivity and communication (M2M), vitally important for machine collaboration and process optimization [66]. Computer-to-computer communication brings much greater efficiency and extraordinary security in production units, from factory halls to agriculture. Literally, machine-to-machine is synonymous with technology that communicates without human intervention. M2M communications change some processes by giving more data to the enterprises, and they will require companies to train employees for these purposes. In addition, the integration of M2M elements will require better integration capabilities and the creation of reliable complex networks with a higher level of security [67]. Rao [26] 
and his team described a farm of "no farmers" where cows can be detected by the feeding machines through sensors and M2M communication, and where the digital sensor capsules inside the cow send reports that the cow is fertile. Worldwide, the automotive, energy, transportation, logistics, consumer electronics, and ultimately retail industries are becoming the new view of new M2M applications [66]. M2M communication offers autonomous communication between intelligent encoders and drives and delivers greater value in the transport sector [17]. M2M communication systems implement automated data communication between machine-type communication (MTC) devices, creating a basic communication infrastructure for IoT and 5G networks [68,69]. M2M communication will be provided both between physical objects and between their cloud-based digital counterparts [70]. Depending on the location of the distant objects relative to the network, cloud computer technology is referred to [71]. In the future, cloud robotics will be used with real-time connectivity. A higher level of M2M communication is related to the Internet of things (IoT), which is a designation for a much more intelligent interconnection of various products, devices, etc. [72]. The key elements are miniature sensors, representing an almost ubiquitous image recognition technology capable of recognizing people, buildings, and other objects [73].

\subsection{Sharing and Using Data with Suppliers and Customers}

Enterprises face a precarious environment and strive to achieve greater cooperation in the supply chain to leverage the resources and knowledge of their suppliers and customers [74]. In such a chain, this cooperation takes place through electronic data interchange (EDI) [53]. Using and evaluating multidimensional process knowledge is considered an effective strategy to improve the competitiveness of the enterprises [75]. Sharing forecasting information helps supply chain parties better match demand and supply [76]. The information is used to update variations in seasonal product demand [77]. Information needs to be shared to achieve an efficient supply chain [78]. Optimum supply chain performance requires manufacturers to truly inform other partners of their original forecast [79]. By Croson and Donohue [80], it is useful for the enterprises to share sales data (POS - Point of Sale materials), especially to reduce the bullwhip effect. Christopher, in connection with data sharing and supplier and customer integration, discussed "demand chain management", linking supply chain management with marketing, bringing agile and lean properties to chains [81]. Demand chain is defined by (1) managing integration between demand and supply processes, (2) managing the structure between integrated processes and customer segments, and (3) managing the working relationship between the marketing and supply chain [82]. In addition, the enterprises are able to share product life-cycle information and focus on product design [83]. In practice, it is the co-design, visualization and production analysis, and joint research and design [84]. This creates a variety of systems for exchanging and sharing product information between users and platforms $[85,86]$.

\subsection{Use of Virtual Reality, Simulation, and Digital Twins}

Simulation is defined as an imitation of a real thing, a state, or a process. Generally, it implies displaying or modeling some key features and behavior of some physical or abstract systems for testing, optimization, and education. Product and process simulations are used extensively in production, especially processes of visualization, representation, simulation, modeling, and interpretation. Enriching digital simulations with sensor data brings reality closer and improves the accuracy of simulation results [87]. Virtual reality (VR) is broadly defined as a computer-generated three-dimensional (3D) world [88], and an environment that simulates complex situations and contexts in real life and allows people to immerse, navigate, and communicate [89]. A key feature of virtual reality is real-time interactivity. VR systems generally track the movement of hand-held objects and the user's head and limbs, and the received data are used to determine the user's view, navigation, interaction with objects, and possible movement of the virtual body, known as an "avatar" [90]. Virtual reality by Steuer [91] is technological hardware that includes a computer, an imaging helmet, headphones, and motion-sensory gloves. The main areas of VR application include healthcare [92]. The concept of 
augmented reality must be distinguished from the concept of virtual reality. Augmented reality (AR) is a special application providing its users with a direct or indirect view of the real world, whose parts are complemented, expanded, and enriched with additional digital visual elements [93,94]. Examples include end-to-end applications, viewing glasses, and projection of information in a car directly onto the windshield. The use of simulation to control and optimize products and manufacturing systems in real time is a concept known as the digital twin [95], which is considered as another step in modeling, simulation, and optimization of technologies [96]. Digital twins are defined as a digital replication of both living and inanimate entities that enable seamless data transfer between the physical and virtual worlds [97]. Digital twins are a mirror image of a real-time physical process [98]. The concept of using "twins" comes from the Apollo NASA (National Aeronautics and Space Administration) program; later, it was used also in aviation, such as the "Iron Bird" [96]. Digital twin devices offer a platform for the development, testing, improvement, and upscale of the manufacturing environment [99]. Digital twin technology is considered a key technology for the realization of cyber physical systems [100]. The application of simulation techniques brings digital twins to life and makes them experimentable; the digital twins become known as experimentable digital twins (EDTs). Initially, these EDTs communicate with each other purely in the virtual world. In this way, complete digital representations of the respective real assets and their behavior are created. Real-estate EDT networking leads to hybrid application scenarios in which EDT is used in combination with real hardware, delivering complex control algorithms, innovative user interfaces, and smart models for smart systems [101].

\section{Materials and Methods}

The main aim of the paper was to analyze the readiness of enterprises to implement Industry 4.0 in the period 2018-2019. The first partial aim of the paper was to compile an index of evaluation of the level of Industry 4.0 in enterprises based on the results of a survey. The second partial aim was the statistical verification of the consistency of the index with further results from the questionnaire survey.

The preparation of the research sample firstly included the identification of the number of enterprises used for the questionnaire survey. Based on CSU (Czech Statistical Office) data, it was found that, in the Czech Republic, there were 175,894 enterprises in the manufacturing industry in 2017, of which $7.1 \%$ were small, medium, and large enterprises, i.e., a total of 12,470 subjects [102]. Approximately 2500 enterprises were approached to ensure that a $95 \%$ confidence level condition was met at a $5 \%$ margin of error and at a discarded $15 \%$ return on the questionnaires. The data were collected on the basis of interviews with business managers, firstly addressed electronically. Of the total number of respondents, 314 enterprises agreed to cooperate and participate in a questionnaire survey with a return rate of $12.5 \%$. The authors of the paper and university students were present at the meetings with the enterprises and in the process of completing the questionnaires. The establishment of the research was approached in two stages (two research waves): first in February-March 2018 and then in January-May 2019.

As part of Industry 4.0 research, the research sample consisted of 276 enterprises reporting their data (38 out of 314 questionnaires were excluded based on these criteria: at least 10 employees, one year on the market, and completeness of survey). The amount of obtained data was further specified in terms of business characteristics, i.e., size and technology demands (Table 1). The first wave of the research was used to create the Industry 4.0 index (VPi4), whereas the second wave of the research was used to check and compare the results achieved. Characteristics of the research samples according to the research waves were as follows:

- $\quad$ First wave of research (year 2018) - 164 enterprises (60\% of data sample);

- Second wave of research (year 2019)-112 enterprises (40\% of data sample). 
Table 1. Research sample characteristics.

\begin{tabular}{cccc}
\hline Group & Category of Group & 1st Wave & 2nd Wave \\
\hline \multirow{2}{*}{ Size } & Small enterprise (10-49 employees) & $39.0 \%$ & $36.6 \%$ \\
& Medium enterprise (50-249 employees) & $28.7 \%$ & $30.4 \%$ \\
& Large enterprise (over 250 employees) & $32.3 \%$ & $33.0 \%$ \\
\hline \multirow{2}{*}{ Technological intensity } & High-tech and medium high-tech intensity (HTI) & $51.2 \%$ & $58.0 \%$ \\
& Of which high-tech sector (HTS) & $7.9 \%$ & $8.9 \%$ \\
& and medium high-tech sector (MHTS) & $43.3 \%$ & $49.1 \%$ \\
\cline { 2 - 4 } & Low-tech and medium low-tech intensity (LTI) & $48.8 \%$ & $42.0 \%$ \\
& Of which low-tech sector (LTS) & $12.2 \%$ & $27.7 \%$ \\
\hline
\end{tabular}

Table 1 describes the research sample in terms of the size of the enterprises and their technological intensity.

Classification of the enterprises by size was based on the number of employees of the enterprise, as defined by the methodology of the European Commission [103]. Table 1 shows that, in the first wave sample, there were $39.0 \%$ small enterprises, $28.7 \%$ medium-sized enterprises, and $32.3 \%$ large enterprises as the most common. The composition of enterprises in the second wave of research was very similar.

Table 1 shows the distribution of enterprises in terms of their technological intensity, with the enterprises with higher technological intensity (HTI) and the enterprises with lower technological intensity (LTI) according to the methodology of the Czech Statistical Office [102]. In the Czech Republic and in our research in both waves, the groups were comparable. The only difference was the representation of the enterprises from the low-tech sector (LTS) and medium low-tech sector (MLTS) in the area with lower technological intensity in the first and second waves of research.

- HTI: Engineering and electro-technical production (CZ-NACE groups 24-30), chemical, paper, and non-metallic production (CZ-NACE groups 17-23).

- LTI: Production of products for domestic use (CZ-NACE Groups 13-16, 31-32), food production industry (CZ-NACE Groups 10-12).

The questionnaire focused on main groups of Industry 4.0 characteristics (observed phenomena). The items of the questionnaire were defined with the support of 34 managers and their expert evaluation within the framework of the qualitative research. The main part of the questionnaire consisted of 17 variables characterizing different technologies of Industry 4.0 used by the enterprises (data collection, cloud storage, data analysis, people capability, IT infrastructure, information systems, M2M, robots, mobile terminals, using sensors, learning software, sharing data, virtual reality, additive manufacturing, i.e., 3D print, nanotechnology, drones, and autonomous vehicles). The areas are described in detail in Section 2. In addition, four identification characteristics were measured for the enterprises, i.e., size according to the number of employees, field of activity, technological intensity, and type of owner. The questionnaire also included questions about whether the enterprises had a formulated strategy, whether they planned on investing in technology, and a subjective assessment of the level of Industry 4.0 in their organization.

\subsection{Exploratory Factor Analysis}

The factor analysis was chosen to classify the most important variables affecting the level of enterprise readiness for Industry 4.0 into groups. The central aim of factor analysis is the orderly simplification [104] of several interrelated measures using mathematical procedures. The goal of the analysis is to reduce the number of variables through fewer common factors and to reveal the structure of relationships between the variables. Factor analysis in the broad sense comprises both a number of statistical models and a number of simplifying procedures for the approximate description 
of data [105]. The basis of factor analysis is the assumption that the observed covariance (relationships, i.e., correlations) between the variables is the result of the action of common factors and not the interrelationship between the variables. Gorsuch [106] pointed out that the aim of factor analysis is to summarize the interrelationships among the variables in a concise but accurate manner as an aid in conceptualization. Each factor represents an area of generalization that is qualitatively distinct from that represented by any other factor. A measure of the degree of generalizability found between each variable and each factor is calculated and referred to as a factor loading.

We used exploratory factor analysis (EFA) to explore the main dimensions and generate a new index of Industry 4.0. The scales of the items used in factor analysis were assessed on a scale of 1-4, using the same range as Veza [107] in the survey, to evaluate the Industry 4.0 maturity level of Croatian enterprises. This scale achieved better pilot research results than 1-5 used by Frank [108] or Schumacher [109] to determine the implementation of different technologies in manufacturing companies.

The factor analysis helped in particular to determine the internal structure of covariance of variable indexes and to differentiate different groups of the factors. The suitability of data structure for factor analysis was analyzed by Bartlett's test of sphericity [110] and the Kaiser-Meyer-Olkin (KMO) test [111]. Bartlett's test checked that the observed correlation matrix diverged significantly from the identity matrix at $\alpha=0.05$ with a $p$-value of $3.021 \times 10^{-15}\left(\chi^{2}=96.243\right.$, degrees of freedom $\left.(\mathrm{df})=12\right)$. Subsequently, the Kaiser-Meyer-Olkin sample adequacy ratio was calculated, and the value was 0.8495. Such a value was deemed high (higher than 0.7), making factor analysis very appropriate [112]. Tabachnick and Fidell [113] recommended inspecting the correlation matrix for correlation coefficients over 0.30 . Many correlation coefficients do not meet this requirement, but almost all of these coefficients were statistically significant at the level $\alpha=0.05$.

\subsection{Statistical Analysis}

The results of the research were further processed using statistical analysis. The aim of this analysis was to compare the results with the Industry $4.0 \mathrm{VPi} 4$ index.

Firstly, the VPi4 index distribution within the first wave of the research was compared with the index results in the second wave of the research. Due to the abnormality of the data, it was necessary to use the non-parametric Mann-Whitney-Wilcox test for the independent samples. In this case, we expected the samples to be similar. Working hypotheses, which formed the subject matter of verification at the $5 \%$ level of significance, were as follows:

- $\quad \mathrm{H}_{0}$ : The VPi4 indexes based on data from the first research wave and the second research wave are identical populations.

- $\quad \mathrm{H} 1_{\mathrm{A}}$ : The VPi4 indexes based on data from the first research wave and the second research wave are different populations.

Furthermore, the dependence between the subjective perception of Industry 4.0 level and the VPi4 index was tested using Person and Spearman correlation coefficients. The index was expected to correlate to a certain extent with the subjective perception of the situation in the enterprise. Working hypotheses, which formed the subject matter of verification at the $5 \%$ level of significance, were as follows:

- $\mathrm{H} 2_{0}$ : There is no dependency between the perception of Industry 4.0 in enterprises and the VPi4 index.

- $\mathrm{H} 2_{\mathrm{A}}$ : There is a dependency between the perception of Industry 4.0 in enterprises and the VPi4 index.

Furthermore, the hypotheses about the impact of technological intensity of the industry on the level of Industry 4.0 in the enterprises (expressed through the VPi4 index) were tested. The Mann-Whitney test was used for this purpose. It was assumed that the index would reach higher values in the enterprises with higher technological demands. For this purpose, the analysis was carried 
out separately for high-tech and low-tech enterprises, and the results were then compared. Working hypotheses, which formed the subject matter of verification at the $5 \%$ level of significance, were as follows:

- $\quad \mathrm{H}_{3}$ : There is no difference between the level of Industry 4.0 (VPi4) in high-tech and medium high-tech enterprises (HTI) and in low-tech and medium low-tech enterprises (LTI).

- $\quad \mathrm{H} 3_{\mathrm{A}}$ : There is a difference between the level of Industry 4.0 (VPi4) in high-tech and medium high-tech enterprises (HTI) and in low-tech and medium low-tech enterprises (LTI).

Statistical evaluation of tests was performed using Statistica 12 and R software.

\section{Results}

The results are divided into three sub-sections: factor analysis, index of Industry 4.0, and verification and evaluation of Industry 4.0 index.

\subsection{Results of Factor Analysis}

Factor analysis was based on the variables the enterprises were asked about in relation to their implementation of Industry 4.0. Several variants of factor analysis were performed with various parameters with different items of the questionnaire.

Firstly, all 17 monitored items from the questionnaire were included in the exploratory factor analysis. The results of the principal component analysis method showed that four factors explained a total of $51 \%$ variance. However, the fourth factor contained only two items, of which drones had a negative factor loading of $f 4=-0.45$ and autonomous vehicles reported a factor loading of $f 4=+0.78$. Further rotation and testing did not improve the situation, and these items were, therefore, excluded from the analysis. The highest factor loadings for additive manufacturing $f 2=+0.37$ and nanotechnology $f 2=+0.32$ were very low $(<0.4)$. Items which have a load less than 0.4 on any factor should be removed and the analysis should be re-run [114]. This means that these items did not saturate the factors sufficiently. In addition, they were not used to a great extent in the enterprises surveyed (usage of these variables in our results: nanotechnology $4.0 \%$, drones $0.7 \%$, additive manufacturing only $9.1 \%$, and autonomous vehicles $2.9 \%$ ). These items were, therefore, also eliminated from the factor analysis.

Finally, 13 variables were selected for the final design. As mentioned in the methodology, the suitability of the factor analysis was verified using the KMO index and the Bartlett test.

\subsubsection{Factors Extraction}

Factor extraction was performed using the principal component analysis method. This method is based on a large number of variables to find a smaller set of new variables (Table 2 with less redundancy to provide the best possible data representation [115]. The three factors found accounted for a total of $52.8 \%$ variance. The first factor explained $34.6 \%$ variance. The Eigen value of the second factor was 1.2 , and the variance explained by this factor was $9.3 \%$. The third factor then explained $8.9 \%$ of the variance (see Table 2). The remaining factors were always less than $5 \%$ of the total variance and their Eigen values were less than one. Based on the Kaiser-Guttman criterion, it was, therefore, appropriate to interpret only the first three factors, as they explained more variance than the original variables.

Table 2. Factor extraction using principal component analysis.

\begin{tabular}{cccc}
\hline Value & Eigen Value & \% Total Variance & Cumulative \% \\
\hline 1 & 4.4920 & 34.5540 & 34.5540 \\
2 & 1.2067 & 9.2826 & 43.8365 \\
3 & 1.1689 & 8.9911 & 52.8277 \\
\hline
\end{tabular}




\subsubsection{Factor Loadings and Rotation}

In factor extraction, factor loads were calculated for each item, representing the correlations between the factors and the variables. They could be used to interpret the factors. Thus, by processing the data, three rather consistent factors were extracted (without rotation). Since initial factor extraction usually does not provide interpretable results, it was done using the Varimax method. The primary factor load aggregate variables are marked in bold in Table 3. The values in Table 3 represent the factor loads of the rotating factors. The sign of factor load expresses the opposite relation to the given factor. In addition to the Varimax method, other methods were used, but it was shown that these results are best interpretable.

Table 3. Factor loadings. Primary factor load aggregate variables are marked in bold. IT-information technology; MES-manufacturing execution system; ERP-enterprise resource planning; M2M-machine-to-machine communication; 3D—three-dimensional.

\begin{tabular}{cccc}
\hline Variable & Factor $\mathbf{1}$ & Factor $\mathbf{2}$ & Factor 3 \\
\hline We collect data & $\mathbf{0 . 8 2 1 2}$ & 0.2961 & 0.0451 \\
Data storage in the cloud & $\mathbf{0 . 6 2 6 0}$ & 0.0023 & 0.3342 \\
We analyze the data & $\mathbf{0 . 8 6 0 3}$ & 0.1839 & 0.0997 \\
We have the right people & $\mathbf{0 . 6 0 9 4}$ & -0.0134 & 0.1901 \\
IT infrastructure & 0.4481 & $\mathbf{0 . 5 2 5 1}$ & -0.0306 \\
Information systems MES, ERP & 0.1367 & $\mathbf{0 . 7 5 7 7}$ & -0.1363 \\
Linked data (M2M) & 0.3207 & $\mathbf{0 . 5 7 5 0}$ & 0.1562 \\
The use of robots & 0.1658 & $\mathbf{0 . 5 4 4 9}$ & 0.4303 \\
Mobile terminal equipment & 0.1383 & $\mathbf{0 . 5 4 4 8}$ & 0.4186 \\
Using sensors & 0.3203 & $\mathbf{0 . 5 8 4 4}$ & 0.3058 \\
Using learning software & 0.1950 & 0.3306 & $\mathbf{0 . 4 4 4 8}$ \\
Sharing data with suppliers & 0.2245 & -0.0315 & $\mathbf{0 . 6 6 9 6}$ \\
Use of virtual reality & 0.0643 & 0.0797 & $\mathbf{0 . 6 8 4 2}$ \\
Autonomous vehicles & & Eliminated & \\
Additive manufacturing (3D printing) & & Eliminated & \\
Nanotechnology & & Eliminated & \\
Drones & & Eliminated & \\
\hline Variance explained & 2.7416 & 2.3541 & 1.7719 \\
Total & 0.2109 & 0.1811 & 0.1363 \\
\hline
\end{tabular}

In terms of interpretation and for model purposes, the factors were identified as levels $1-3$ of Industry 4.0 in the enterprises. It is clear from Table 3 that level 1 was primarily saturated with the human capital variable, collecting data, storing data in the cloud, and analyzing data. These variables have in common that they focus on working with data and the availability of human capital, i.e., the need to operate equipment and technology. Level 2, on the other hand, included all the variables related to the core infrastructure of industry 4.0. This means IT infrastructure, the presence of MES and ERP information systems, M2M-based data interconnection, the use of robots and their arms in production, mobile devices, and sensors. Level 3 included a higher level of Industry 4.0 that can be expressed through the use of learning software, data sharing with suppliers, and virtual reality. The items autonomous vehicles, additive manufacturing, nanotechnology, and drones were eliminated in the preliminary factor analysis (see Section 4.1) and not used for this run of factor analysis.

\subsection{Index of Industry 4.0}

The results of the factor analysis were further used to create an index for the implementation level of Industry 4.0 (VPi4) in the enterprise. Based on these data, it was possible to divide 13 areas into three levels of Industry 4.0 implementation into the enterprise, using factor analysis, where the numbers after each area represent their factor load. 
The first level of introducing Industry 4.0 into an enterprise consists of the following areas:

- We have the right people (mechatronics, mounter, technologist) - 0.61 ;

- We collect data-0.82;

- Data storage in the cloud-0.63;

- We analyze data-0.86.

The second level of introducing Industry 4.0 into an enterprise consists of the following areas:

- $\quad$ IT infrastructure (speed, stability) -0.53 ;

- $\quad$ MES, ERP-0.75;

- We use linked data (M2M) - 0.58 ;

- Use of robots, robotic arms (in production and elsewhere)-0.54;

- Mobile terminals-0.54;

- Use of sensors-0.58.

The third level of introducing Industry 4.0 into an enterprise consists of the following areas:

- Use of learning software-0.44;

- $\quad$ Suppliers can use our data (response options, predictions) - 0.67 ;

- Use of virtual reality (digital twins, simulation) - 0.68 .

Figure 1a below shows the data distribution in terms of VPi4 percentage; the intervals were created automatically for legibility. The most frequent interval was $39 \%-52 \%$ with a frequency of 37 enterprises, followed by an interval of $26 \%-39 \%$ with a frequency of 36 enterprises. The least represented interval was $78 \%-91 \%$, where there were seven enterprises.

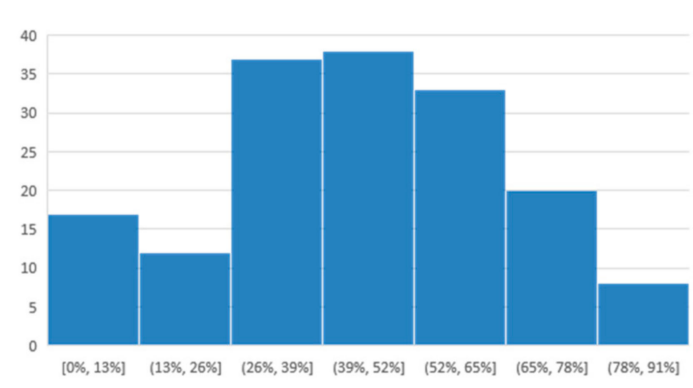

(a)

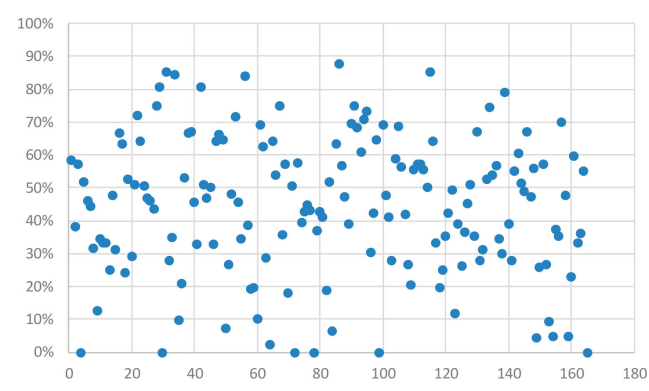

(b)

Figure 1. The enterprises by the index of Industry 4.0 (VPi4) percentage: (a) distribution of the enterprises by intervals; (b) total distribution.

Figure $1 \mathrm{~b}$ shows the 164 enterprises evaluated under the first wave of the research ( $x$-axis) with their percentage of Vpi4 (y-axis). As seen from the chart, most of the enterprises were between $29 \%$ and $60 \%$. Conversely, in the lower quartile, there were $29 \%$ of enterprises, while there were $60 \%$ of enterprises in the upper quartile.

\subsection{Verification and Evaluation of Industry 4.0 Index}

The results of the second wave of the research and supplementary questions identifying the subjective perception of the enterprises and the impact of the technological intensity of the industry were also used to assess the results of the Vpi4 index.

On the basis of the results, a scorecard was designed, such that an enterprise is able to determine the level of implementation of Industry 4.0 inside the enterprise based on the answers to the questions. The enterprise finds out the overall score and the fulfilment of different levels of Industry 4.0. At the 
same time, it can also compare the result with other enterprises in the industry where a set of five icons shows the position compared to other enterprises. Each icon shows a $20 \%$ sample distribution (see Figure 2).

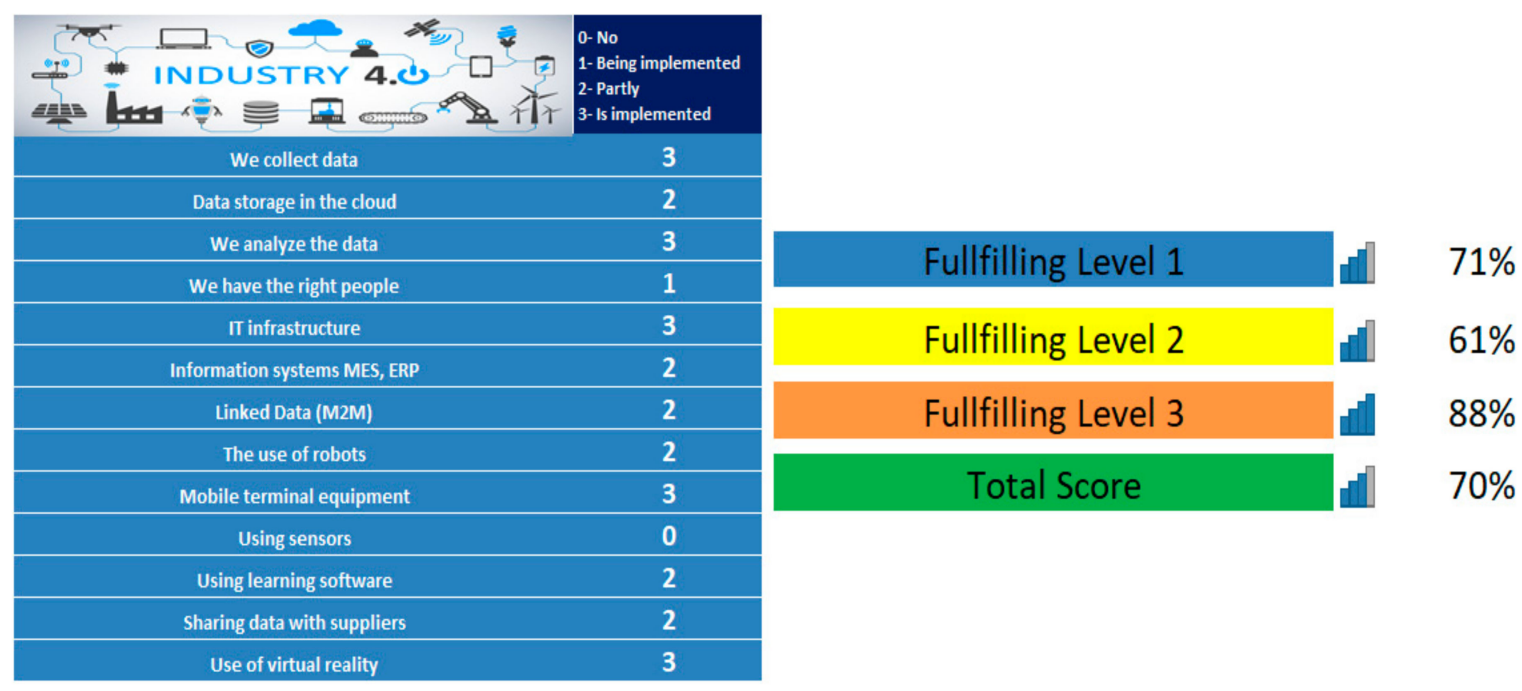

Figure 2. Vpi4 index.

\subsubsection{Industry 4.0 Index Distribution}

The data of the first and second wave of the research were used to evaluate the data distribution. Figure 3 below shows the enterprises at levels 1-3, which are color-coded (each enterprise is shown three times on the graph), with the $y$-axis showing the values of each level and the $x$-axis showing the total Vpi4 as a percentage.

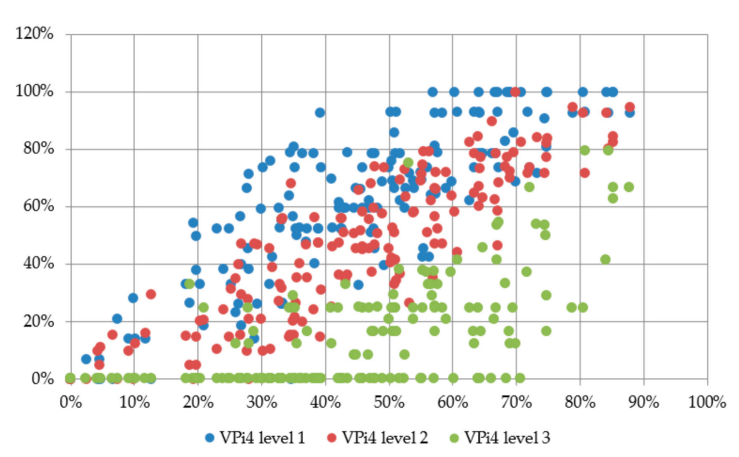

(a)

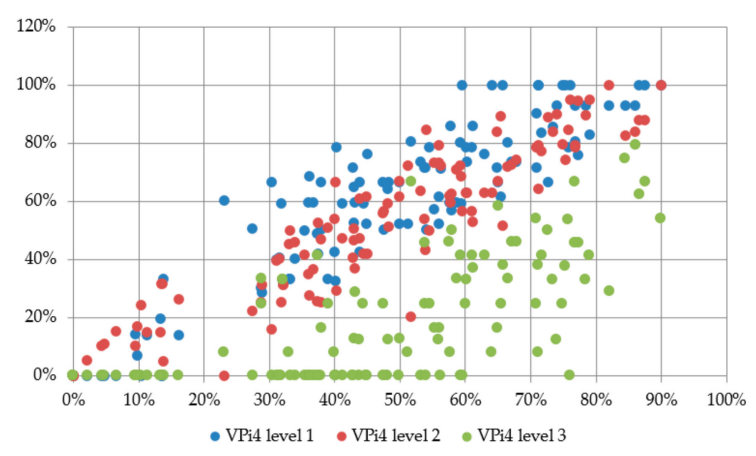

(b)

Figure 3. Evaluation of enterprises by VPi4: (a) distribution of the enterprises in the first wave of the research; (b) distribution of enterprises in the second wave of the research.

Figure 3a shows how the levels overlap; however, most of the enterprises reached the higher level 1 , while the second and third levels featured a score pf zero. The distribution of the enterprises in the second wave of Figure $3 \mathrm{~b}$ was similar. It is interesting to note, for example, that one enterprise achieved a very high overall Vpi4 at $88 \%$, while, at the same time, it had a level 1 score of $93 \%$, level 2 score of $95 \%$, and level 3 score of $67 \%$ (three dots to the right of the graph). In total, five companies in the first wave achieved absolutely zero values in Vpi4.

Furthermore, the VPi4 index distribution was statistically compared, using the samples from the first wave and the second wave of the research. For this reason, Mann-Whitney-Wilcox test statistics were used to compare the samples. Table 4 shows that, at all levels of the VPi4 index except the third 
level, the results of the first and second wave research were identical. Differences were found only in the third level with a $p$-value $=0.0267$. However, the third level of the index is very specific, as higher ranking at this level is often more difficult for enterprises to achieve after the first two levels are met. The enterprises in the second wave achieved a higher level of the VPi4 index at level 3 than in the first wave. The results also show that there was a difference in self-perception and self-assessment of the use of Industry 4.0 for the enterprises in the first and second waves.

Table 4. Industry 4.0 index (VPi4) distribution, using Mann-Whitney-Wilcox test.

\begin{tabular}{ccccc}
\hline Variable & Median w1 & Median w2 & W & $p$-Value \\
\hline VPi4\% total & 44.39 & 49.65 & 8230.0 & 0.1431 \\
VPi4\% level 1 & 55.33 & 57.72 & 8898.0 & 0.6611 \\
VPi4\% level 2 & 47.48 & 53.49 & 8134.0 & 0.1070 \\
VPi4\% level 3 & 27.30 & 33.19 & 7741.0 & 0.0267 \\
Enterprise perception & 2.00 & 3.00 & 6771.5 & 0.0001 \\
\hline
\end{tabular}

The results of the comparison of the index results in the first and second waves of the research show that hypothesis $\mathrm{H}_{0}$ cannot be rejected, as the results of both surveys showed the same distributions.

\subsubsection{Relation of the Index to the Subjective Perception of the Level of Industry 4.0 by the Enterprises}

The relation of the index to the subjective perception of the level of Industry 4.0 by the enterprises was carried out in both waves of the research. The correlation between VPi4 index (\%) and the scale on which enterprises evaluated themselves in relation to Industry 4.0 from 1-5 was analyzed (1-we do not have Industry 4.0; 5-we fully have Industry 4.0). Pearson and Spearman coefficients were used for testing. Firstly, a coefficient of determination of $R^{2}=0.2784$ was calculated; thus, the dependence explained $28 \%$ of the variability of the number of points. On average, the enterprises rated themselves 2.1 with Industry 4.0, with an average rating of the recalculated VPi4 index being $45 \%$ more similar to the score of 3. One-quarter of enterprises had a VPi4 value below $29 \%$, with the upper quarter having a value above $60 \%$. In terms of their own perception, $50 \%$ of the enterprises ranged from $1-3$ on a five-point scale. As also reported by the minima and maxima, some of the enterprises did not achieve any points in the VPi4 index. The maximum was $88 \%$ and 34 points in VPi4.

The normalization of the data of both variables was verified by the Shapiro-Wilk test, with the $p$-value of VPi4\% $=0.09$ assuming the normality of the data, as also shown by the histogram. With the perception of Industry 4.0 by the enterprises, the $p$-value test was close to zero; therefore, the normality of the data was not assumed. The results of the correlation of both variables are shown in Table 5 . Here, on the basis of a $p$-value $=0.0000$, the null hypothesis of independence was rejected in favor of the alternative using the Pearson coefficient at the significance level of $5 \%$. We proved the existence of a linear dependence, which was also proven by the positive Pearson correlation coefficient (0.5277). At the same time, in terms of Spearman correlation, where the $p$-value was very close to zero with $R=0.5147$, the null hypothesis was rejected in favor of $\mathrm{H} 2_{\mathrm{A}}$ on the dependence of both variables.

Table 5. Relation to subjective perception of Industry 4.0, based on Pearson and Spearman coefficients.

\begin{tabular}{|c|c|c|c|c|c|c|c|}
\hline \multirow[b]{2}{*}{ Research } & \multirow[b]{2}{*}{ Variable } & \multicolumn{3}{|c|}{ Pearson } & \multicolumn{3}{|c|}{ Spearman } \\
\hline & & Perception & VPi4 & $p$-Value & Perception & VPi4 & $p$-Value \\
\hline \multirow{2}{*}{ Wave 1} & Perception & 1.0000 & 0.5277 & \multirow{2}{*}{0.0000} & 1.0000 & 0.5147 & \multirow{2}{*}{0.0000} \\
\hline & Index VPi4 & 0.5277 & 1.0000 & & 0.5147 & 1.0000 & \\
\hline \multirow{2}{*}{ Wave 2} & Perception & 1.0000 & 0.4129 & \multirow{2}{*}{0.0001} & 1.0000 & 0.4054 & \multirow{2}{*}{0.0001} \\
\hline & Index VPi4 & 0.4129 & 1.0000 & & 0.4054 & 1.0000 & \\
\hline
\end{tabular}


Similarly, a second questionnaire survey was used for the second wave of the research (Table 5). The coefficient of determination was lower than in the first wave of the research $\left(R^{2}=0.1705\right)$. Dependence, therefore, explained only $17 \%$ of the variability. In the normality verification by the Shapiro-Wilcox test, the values were low to zero in both cases. Therefore, the normality of data, for the VPi4 index and the perception values of Industry 4.0 by the enterprises, was not considered. It was, therefore, better to compare the dependence of the Spearman coefficient. Its value was 0.4054 , i.e., compared to the results in the first wave, the level of dependence was lower. Its value was, however, statistically significant.

Given the proven dependence in both surveys, it was possible to conclude the correct setting of VPi4 by means of factor analysis and the suitability of the questions, as it largely corresponded to the perception of the enterprises in terms of Industry 4.0.

\subsubsection{Relation of the Index to Intensity of Technology and Index Weighting}

The relation to the intensity of technology in the industry was tested in the first wave of the research only (Table 6). The Mann-Whitney test determined the null hypothesis at the sample significance level of $\alpha=0.05$, where $X=$ high-technology sector difficulty and $Y=$ low-technology sector difficulty. The hypotheses were tested, providing $\mathrm{H} 3_{0}=x 0.50-y 0.50=0$ and $\mathrm{H} 3_{\mathrm{A}}=x 0.50>y 0.50$, as viewed from VPi4. As shown in the table below, the null hypothesis of both samples was rejected when the $p$-value was close to zero, and a positive $Z$ confirmed the alternative hypothesis, claiming that the higher-tech enterprises have a higher level of Industry 4.0 (VPi4).

Table 6. Intensity of technology levels (HTI—high-tech intensity; LTI—low-tech intensity), based on Mann-Whitney test.

\begin{tabular}{cccccc}
\hline Variable & Sum of HTI & Sum of LTI & U & Z & $p$-Value \\
\hline VPi4\% total & 7672.5 & 5857.5 & 2617.5 & 2.4410 & 0.0146 \\
VPi4\% level 1 & 7178.5 & 6351.5 & 3111.5 & 0.8159 & 0.4146 \\
VPi4\% level 1 & 7751.5 & 5778.5 & 2538.5 & 2.7009 & 0.0069 \\
VPi4\% level 2 & 7354.5 & 6175.5 & 2935.5 & 1.3949 & 0.1631 \\
Enterprise perception & 7295.5 & 6234.5 & 2994.5 & 1.2001 & 0.2298 \\
\hline
\end{tabular}

Interestingly, it was not possible to reject this hypothesis for the perception of the enterprises from the perspective of Industry 4.0, with a $p$-value of 0.2298 ; therefore, this hypothesis could not be rejected, and we can further assume that the high- and low-tech enterprises saw themselves in a similar way. The hypothesis testing also failed to reject the null $\mathrm{H} 3_{0}$ hypothesis at levels 1 and 3 of Industry 4.0 implementation, as the $p$-values were greater than $\alpha$. On the other hand, for the second phase of Industry 4.0 implementation, it was possible to prove the differences between the two groups. The enterprises with higher technological demands were often more successful.

The VPi4 index was adjusted for comparing enterprises with different intensities of technology. The Mann-Whitney test was used to compare more independent samples where the $p$-value did not indicate statistically significant sectoral differences from the entire sample (Table 7), except for LTS, where a $p$-value (0.0184) indicated a difference at the 0.05 level of significance. For this reason, it was necessary to adjust the index (index obtained by the median difference of 0.0899) for LTS companies, so that their results could be compared with the values of other groups. This fact was logical in terms of the lower use of technologies that were included in VPi4 for enterprises belonging to the low-technology sector. After adjusting the index for LTS enterprises, the Mann-Whitney test was re-conducted, where no significant difference between the whole sample and LTS was found ( $p$-value $=0.0967$ ). 
Table 7. Intensity of technology sectors, based on Mann-Whitney test. M-medium; HT—high-tech; LT-low-tech; S-sector.

\begin{tabular}{cccc}
\hline Variable & $\mathbf{U}$ & \multicolumn{1}{c}{$\mathbf{Z}$} & $\boldsymbol{p}$-Value \\
\hline HTS vs. data sample & 819.5 & -1.3833 & 0.1665 \\
MHTS vs. data sample & 5325.5 & -1.0364 & 0.2999 \\
MLTS vs. data sample & 1370.0 & -1.1984 & 0.2307 \\
LTS vs. data sample & 3907.0 & 2.3572 & 0.0184 \\
\hline
\end{tabular}

\section{Discussion}

In relation to the impact of Industry 4.0 , this paper proved that $62 \%$ of the enterprises feel influenced by Industry 4.0. According to research (sample of 105 enterprises) of the Confederation of Industry of the Czech Republic [116], 65.7\% of companies started implementing Industry 4.0 because it is important for their future. In comparison, the research of Sommer [5] reported that $82 \%$ of the enterprises in Germany feel ready for digitalization (a sample of 247 enterprises), and there were $68 \%$ of 28 enterprises mentioned by Schulze [117], questioned whether they used technology associated with Industry 4.0. Other influences include the degree of cooperation of SMEs (Small and Medium-sized Enterprises) with universities and research centers mentioned by Sastoque et al. [118].

Firstly, we discuss the structure of the VPi4 index levels. The initial level of index includes the basic requirements of Industry 4.0 such as well-qualified (the right) people [119], and processes of data collecting [120], storage in the cloud [121], and analysis of data [122]. These processes and variables are necessary for higher levels of Industry 4.0 and can be limits for the future development and introduction of Industry 4.0 implementation. The second level of the index consists of necessary infrastructure which is needed to operate with technologies. This level has more parts, such as using sensors for collecting data [121], IT infrastructure including MES [123], ERP information systems [123], linked data via M2M (or IoT), robots [44], and user-end technologies such as mobile terminals [121]. The last level is more advanced in terms of using learning software [122], virtual reality, and simulations including digital twins [97] or sharing data with other parties [124].

Furthermore, we discuss the findings and results of similar models of Industry 4.0. There is still no consensus on which model or index is most relevant to determine the level of Industry 4.0 introduction and implementation. Applications foreseen are not only in the high-technological industry but also in other sectors and branches.

Stefan et al. [125] emphasized considering the same meaning of three dimensions-technology, organization, and personnel—in assessing the level of Industry 4.0, as done by Block [126]. However, these dimensions were classified in more detail into three additional levels, assigning them four to seven characteristics. The characteristics, identical to those used in this paper, include data storage, IT infrastructure, and data evaluation. On the other hand, they emphasized data security, process methodology, and personnel development, in contrast to this paper. They set target value criteria for all these characteristics. In the proposed model, they defined criteria, relations, and dependencies between these dimensions to help the enterprises classify the current state of the implementation of Industry 4.0 and identify opportunities for improvement.

Scremin [127] also divided the Industry 4.0 enterprises into three main dimensions-strategy, readiness, and performance-identifying a number of additional areas (2-3) within each dimension, which they then subdivided into more detailed factors that influence the dimensions. Identical factors within VPi4 include IT infrastructure, data sharing, providing data to suppliers, data analysis, and employees.

Ślusarczyk [124] used secondary data at the level of the United States of America (USA), Germany, Japan, and Poland for his research and concluded that $80 \%$ of the enterprises perceive Industry 4.0 as very significant. This can be seen as a similar value to that published in this paper, as, out of $1018,62 \%$ of SMEs responded in the same way. It is important to note that the research of Ślusarczyk [124] was based on data from large enterprises in the US, Germany, Japan, and Poland, which are technologically 
highly developed countries featuring large enterprises. In this paper, the importance of Industry 4.0 was reported as also increased according to the size of the enterprise, as the medium-sized enterprises reached $74 \%$. It can, therefore, be assumed that large enterprises would reach $80 \%$.

Shumacher, Erol and Sihn [109] conducted an assessment of the readiness to implement Industry 4.0, as well as the maturity of the enterprises in this respect. For this purpose, they created a model evaluating the enterprise in nine dimensions (strategy, leadership, customers, product, processes, culture, people, legislation, technology), and each of these dimensions was divided into other sub-parts, which were evaluated on a five-point scale in their questionnaire (not implemented (1) to fully implemented (5)) - this scale also confirmed the accuracy of the four-degree scale in the research (1-we do not use it, 2-being implemented, 3-we use it partially, 4-implemented). From the results of the research, it is evident that the enterprises considered the dimension of the product and people as the most important. The results of this work show that companies mostly deployed IT infrastructure. They then assigned weights to these parts and made readiness calculations. They proposed this model for the enterprises as a means of self-assessment. These authors designed their model very generally, as some dimensions are very difficult to evaluate within subjective perception. For this reason, this paper used a specifically focused indicator, which does not aim to evaluate all the factors, but only the factors related to the technology possible to be evaluated by the enterprise itself.

Frank, Dalenogare, and Ayala [108] conducted a cross-sectional survey among 92 Brazilian manufacturing enterprises, as they identified them as the most affected by Industry 4.0, similar to this paper. They verified that the level of Industry 4.0 implementation depends on the size of the enterprise, as in this work, where it was shown that large enterprises achieve significantly higher VPI $\%$ and Industry 4.0 affects SMEs. They also found enterprises with an advanced level of Industry 4.0 (also divided into three levels). They identified automation, virtualization, and flexibility as the key criteria and barriers to a high level of Industry 4.0.

Durana, Kral, Stehel, Lazaroiu, and Sroka [128], using factor analysis, described a model of quality culture, the fulfilment of which helps the company in the implementation of Industry 4.0, as the most important factor. They found consistency with the research results in terms of the collection of information and emphasis on employees.

Human resources that were identified as the most significant limit in this paper could not be identified in the research of Industry 4.0 technologies, such as implementation patterns in manufacturing companies [108], because the authors did not include them in the questionnaire. They also asked about the sensors, ERP and MES systems, virtual simulation, robot use, and M2M. The main factors affecting the level of Industry 4.0 in the company were equally divided into three levels as in this paper. Interestingly, their allocation of ERP, MES, and sensors to the first level differed from this research. However, robots and M2M were also assigned by Frank [108] to the second level according to cluster analysis.

Other models that summarized the levels of Industry 4.0 implementation in manufacturing enterprises included a model [122] that set six levels of Industry 4.0 in an enterprise. However, these levels were very difficult to measure as they were measured on the basis of general questions. The enterprises that implemented Industry 4.0 throughout the value chain, innovating business processes, reached the highest levels.

\section{Conclusions}

Industry 4.0 is currently identified as a major factor in the future competitiveness of enterprises. However, the implementation of different technologies varies from one enterprise to another. Based on the performed factor analysis, an Industry 4.0 index (VPi4) was created, which allows the enterprises to determine their current level of Industry 4.0.

The proposed index was statistically verified by supplementary research in the second wave of the research. The consistency of the index was confirmed by the fact that it was not possible to reject the $\mathrm{H} 1_{\mathrm{A}}$ hypothesis of different sample distributions. 
The correctness of the results $\left(\mathrm{H} 2_{\mathrm{A}}\right)$ was also shown by the observed dependence between the subjective perception of the enterprises and the results of the index.

Finally, the model was verified due to the intensity of technology in the industry. It was found that companies with a higher intensity more often achieved a higher index level in terms of Industry $4.0\left(\mathrm{H} 3_{\mathrm{A}}\right)$.

\subsection{Managerial Implications}

The VPi4 index and its methodology allow enterprises to easily identify their own level of technology readiness within Industry 4.0. The index is a tool for managers to set strategic objectives and formulate strategies in line with the challenges of the Fourth Industrial Revolution. It can also be a criterion in deciding on investment plans in terms of selecting priorities for the further development of an enterprise. The proposed solution allows better assessment of strategic initiatives in terms of their future return. The managers can also help to decide which projects should be implemented in order to ensure greater synergies. The index includes technologies that need to be implemented in the enterprises, as well as the processes that need to be set up, changed, and reintroduced. In this sense, it can also, in addition to project management, help with the management and identification of key processes in the organization.

\subsection{Theoretical Implications}

Regarding the theory, this paper offers a new way of looking at Industry 4.0 in terms of key processes and technologies. This approach aims to categorize Industry 4.0 components into a clear framework. The proposed index brings a new three-level structure of the Industry 4.0 phenomenon. The main theoretical contribution is, in particular, the determination of the content of the term and the determination of the importance of different factors in the context of the readiness of companies to implement Industry 4.0 concepts. The differences between more technologically and less technologically demanding industries confirm the specifics of different fields in the use of new technologies. This confirms the conclusions of many other researches and the fact that new technologies are largely being introduced, especially in the field of mechanical engineering. The results also indicate that the subjective perception of enterprises of their own level of Industry 4.0 corresponds more or less to the actual situation. The problem, however, is probably the lack of visibility in terms of the current challenges, priorities, and complexity of technology.

\subsection{Limitations and Suggestions for Future Research}

However, this paper has several limitations that must be considered. The VPi4 index does not include some industry-specific applications of Industry 4.0 technologies, such as drone use, 3D printers, nanotechnology, and autonomous vehicles, due to the lower incidence in the monitored businesses. In the early stages of the index preparation and in the initial factor analysis, these factories were included; however, due to the low factor load, they were subsequently removed from the index. All these technologies fell in the highest (third) level of the index. In the future, the authors assume that, with an increase in their use in enterprises, the index will be supplemented by these specific applications. Alternatively, it was considered to create different variants of the index for different industries.

A certain limitation of the paper is related to the method of data collection. At data collection, the expected return on questionnaires was $15 \%$ at a $5 \%$ margin of error and $95 \%$ confidence level. However, the real rate of return was $12.5 \%$. With a usable 276 questionnaires and $95 \%$ confidence level, the margin of error was $5.86 \%$. The error, therefore, slightly exceeded the planned level. Sample size was not representative in the case of proportionality of the Czech Republic enterprise population. The intention of the authors was that the research sample of the enterprises was composed evenly with regard to the size of the enterprises and technological demands of the industry. Therefore, the VPi4 index is not primarily intended to only determine the level of Industry 4.0 in the Czech Republic. 
The main questionnaire survey limits are as follows: the limitations in terms of ignorance of the material and terminology by the respondents [129], as well as the fact that the respondents only reported their individual perspective on the situation [130], and that respondents tried portraying the situation (business) in a better light [131]. For this reason, a personal meeting with the representatives of the enterprises was used, who often liked to show off how Industry 4.0 works in the enterprise. An important limit, as mentioned by Roberts and Giddens $[129,132]$, is related to the accuracy of the survey, as there was a small percentage of responses obtained; thus, the research results were often based on only $10 \%$ of the original sample; this is a problem faced by every research. The questionnaire also omitted the open questions noted by Saunders [133].

In terms of verification of the resulting VPi4 index, the authors plan to perform a confirmatory factor analysis in combination with the structural model equation method to further refine the adjustment of individual factors within the third wave of the research. It will also include the creation of an Industry 4.0 implementation model. However, recent results from the second wave of the research and comparison presented in the paper suggest that this is unlikely to be a significant intervention in the configuration of the coefficients of different variables and index factors. The authors also plan to analyze the relation of the index to the size of the enterprises.

Another disadvantage of the index could be the fact that the enterprises operating in the Czech Republic only participated in the research in both waves. In the case of large enterprises, however, most of these were foreign-owned enterprises, mostly from the European Union (EU), mostly from Germany. In the third wave of the research, the authors are also planning to do research abroad and include enterprises from developed countries such as Japan, the USA, etc.

Lastly, the proposed VPi4 index is only the first output of the Industry 4.0 project, which deals with the issue more comprehensively. Future research will bring further results.

Author Contributions: Conceptualization, J.V. and M.P.; methodology, J.V. and M.P.; validation, J.V.; formal analysis, M.P.; investigation, J.V. and M.P.; resources, J.V. and M.P.; data curation, M.P.; writing-original draft preparation, J.V. and M.P.; writing—review and editing, M.P.; visualization, J.V.; supervision, J.V.; project administration, J.V.

Funding: This research was funded by "EF-150-GAJU 047/2019/S".

Acknowledgments: The authors thank the enterprises taking part in the research.

Conflicts of Interest: The authors declare no conflicts of interest.

\section{References}

1. Weyrich, M.; Schmidt, J.-P.; Ebert, C. Machine-to-Machine Communication. IEEE Softw. 2014, 31, 19-23. [CrossRef]

2. Kelkar, O. Studie Industrie 4.0-Eine Standortbestimmung der Automobil-und Fertigungsindustrie. Mieschke Hofmann und Partner (MHP), Ludwigsburg, Germany. Available online: https://www.mhp.com/fileadmin/ mhp.de/assets/studien/MHP-Studie_Industrie4.0_V1.0.pdf (accessed on 11 November 2019).

3. Pricewaterhouse Coopers PwC-und Strategy\&-Studie: Industrie 4.0 hat Hohes Nutzenpotenzial für Deutsche Unternehmen. Available online: https://www.pwc.de/de/digitale-transformation/pwc-studie-industrie-4-0steht-vor-dem-durchbruch.html (accessed on 8 November 2019).

4. Dörfler, M. Industrie 4.0 ist im Mittelstand Noch Nicht Angekommen. Available online: https://www. marktundmittelstand.de/404/ (accessed on 11 November 2019).

5. Sommer, L. Industrial revolution-Industry 4.0: Are German manufacturing SMEs the first victims of this revolution? J. Ind. Eng. Manag. 2015, 8, 1512-1532. [CrossRef]

6. Tupa, J.; Simota, J.; Steiner, F. Aspects of Risk Management Implementation for Industry 4.0. Procedia Manuf. 2017, 11, 1223-1230. [CrossRef]

7. Zhong, R.Y.; Xu, X.; Klotz, E.; Newman, S.T. Intelligent Manufacturing in the Context of Industry 4.0: A Review. Engineering 2017, 3, 616-630. [CrossRef]

8. Lu, B.H.; Bateman, R.J.; Cheng, K. RFID enabled manufacturing: Fundamentals, methodology and applications. Int. J. Agile Syst. Manag. 2006, 1, 73. [CrossRef] 
9. Mansoor, K.; Ghani, A.; Chaudhry, S.A.; Shamshirband, S.; Ghayyur, S.A.K.; Mosavi, A. Securing IoT-Based RFID Systems: A Robust Authentication Protocol Using Symmetric Cryptography. Sensors 2019, 19, 4752. [CrossRef]

10. Lucke, D.; Constantinescu, C.; Westkämper, E. Smart Factory-A Step towards the Next Generation of Manufacturing. In Proceedings of the Manufacturing Systems and Technologies for the New Frontier, Tokyo, Japan, 26-28 May 2008; Mitsuishi, M., Ueda, K., Kimura, F., Eds.; Springer: London, UK, 2008; pp. 115-118.

11. Tan, P.; Wu, H.; Li, P.; Xu, H. Teaching Management System with Applications of RFID and IoT Technology. Educ. Sci. 2018, 8, 26. [CrossRef]

12. Reis, M.; Gins, G. Industrial Process Monitoring in the Big Data/Industry 4.0 Era: From Detection, to Diagnosis, to Prognosis. Processes 2017, 5, 35. [CrossRef]

13. Smajic, H.; Wessel, N. Remote Control of Large Manufacturing Plants Using Core Elements of Industry 4.0. In Proceedings of the Online Engineering E Internet of Things, Columbia University, New York, USA 15-17 March 2017; Auer, M.E., Zutin, D.G., Eds.; Springer International Publishing: Cham, Switzerland, 2018; pp. 546-551.

14. McAfee, A.; Brynjolfsson, E. Big Data: The Management Revolution. Harv. Bus. Rev. 2012, 90, 60-68.

15. Mayer-Schönberger, V.; Cukier, K. Big Data; Computer Press: Brno, Czech Republic, 2014; ISBN 978-80-251-4119-9.

16. Boyd, D.; Crawford, K. Critical questions for big data: Provocations for a cultural, technological, and scholarly phenomenon. Inf. Commun. Soc. 2012, 15, 662-679. [CrossRef]

17. Laney, D. 3D Data Management: Controlling Data Volume, Velocity, and Variety. Available online: http://blogs.gartner.com/doug-laney/files/2012/01/ad949-3D-Data-Management-Controlling-DataVolume-Velocity-and-Variety.pdf (accessed on 6 February 2001).

18. Berman, J.J. Principles of Big Data: Preparing, Sharing, and Analyzing Complex Information; Elsevier, Morgan Kaufmann: Amsterdam, The Netherlands, 2013; ISBN 978-0-12-404576-7.

19. Gantz, J.; Reinsel, D. Extracting value from chaos. IDC IView 2011, 1142, 1-12.

20. Sivarajah, U.; Kamal, M.M.; Irani, Z.; Weerakkody, V. Critical analysis of Big Data challenges and analytical methods. J. Bus. Res. 2017, 70, 263-286. [CrossRef]

21. Ge, M.; Bangui, H.; Buhnova, B. Big Data for Internet of Things: A Survey. Future Gener. Comput. Syst. 2018, 87, 601-614. [CrossRef]

22. $\mathrm{Xu}, \mathrm{X}$. From cloud computing to cloud manufacturing. Robot. Comput. Integr. Manuf. 2012, 28 , 75-86. [CrossRef]

23. Tsai, C.-W.; Lai, C.-F.; Chao, H.-C.; Vasilakos, A.V. Big data analytics: A survey. J. Big Data 2015, 2, 21. [CrossRef]

24. Tjahjono, B.; Esplugues, C.; Ares, E.; Pelaez, G. What does Industry 4.0 mean to Supply Chain? Procedia Manuf. 2017, 13, 1175-1182. [CrossRef]

25. Ertürk, M.A.; Aydın, M.A.; Büyükakkaşlar, M.T.; Evirgen, H. A Survey on LoRaWAN Architecture, Protocol and Technologies. Future Internet 2019, 11, 216. [CrossRef]

26. Rao, S.K.; Prasad, R. Impact of 5G Technologies on Industry 4.0. Wirel. Pers. Commun. 2018, 100, 145-159. [CrossRef]

27. Leber, J. General Electric Pitches an Industrial Internet. Available online: https://www.technologyreview. com/s/507831/general-electric-pitches-an-industrial-internet/ (accessed on 8 November 2019).

28. Floyer, D. Defining and Sizing the Industrial Internet-Wikibon. Available online: http://wikibon.org/wiki/ v/Defining_and_Sizing_the_Industrial_Internet\#Constraints_on_Adoption_of_the_Industrial_Internet (accessed on 8 November 2019).

29. Fuertes, W.; Reyes, F.; Valladares, P.; Tapia, F.; Toulkeridis, T.; Pérez, E. An Integral Model to Provide Reactive and Proactive Services in an Academic CSIRT Based on Business Intelligence. Systems 2017, 5, 52. [CrossRef]

30. Petrović, M.; Vučković, M.; Turajlić, N.; Babarogić, S.; Aničić, N.; Marjanović, Z. Automating ETL processes using the domain-specific modeling approach. Inf. Syst. E Bus. Manag. 2017, 15, 425-460. [CrossRef]

31. Armbrust, M.; Fox, A.; Griffith, R.; Joseph, A.D.; Katz, R.H.; Konwinski, A.; Lee, G.; Patterson, D.A.; Rabkin, A.; Zaharia, M. Above the Clouds: A Berkeley View of Cloud Computing; Electrical Engineering and Computer Sciences University of California: Berkley, CA, USA, 2009.

32. Buyya, R. Market-Oriented Cloud Computing: Vision, Hype, and Reality of Delivering Computing as the 5th Utility. In Proceedings of the 9th IEEE/ACM International Symposium on Cluster Computing and the Grid, Shanghai, China, 19-21 May 2009; p. 1. 
33. Vaquero, L.M.; Rodero-Merino, I.; Caceres, J.; Lindner, R. A break in the cloud: Towards a cloud definition. ACM SIGCOMM Comput. Commun. Rev. 2009, 39, 50-55. [CrossRef]

34. McKinsey and Co. Clearing the Air on Cloud Computing; McKinsey and Co.: New York, NY, USA, 2009.

35. Jamsa, D.K. Cloud Computing: SaaS, PaaS, IaaS, Virtualization, Business Models, Mobile, Security and More, 1st ed.; Jones \& Bartlett Learning: Burlington, MA, USA, 2012; ISBN 978-1-4496-4739-1.

36. Mell, P.; Grance, T. Perspectives on Cloud Computing and Standards; National Institute of Standards and Technology: Gaithersburg, MD, USA, 2008.

37. Wu, L.; Yang, C. A Solution of Manufacturing Resources Sharing in Cloud Computing Environment. In Proceedings of the Cooperative Design, Visualization, and Engineering, Hangzhou, China, 21-24 October 2018; Luo, Y., Ed.; Springer: Berlin/Heidelberg, Germany, 2010; pp. 247-252.

38. Trakadas, P.; Nomikos, N.; Michailidis, E.T.; Zahariadis, T.; Facca, F.M.; Breitgand, D.; Rizou, S.; Masip, X.; Gkonis, P. Hybrid Clouds for Data-Intensive, 5G-Enabled IoT Applications: An Overview, Key Issues and Relevant Architecture. Sensors 2019, 19, 3591. [CrossRef] [PubMed]

39. Zavoral, P. ICT Revue. Available online: //ictrevue.ihned.cz/ (accessed on 11 November 2019).

40. Parn, E.A.; Edwards, D. Cyber threats confronting the digital built environment: Common data environment vulnerabilities and block chain deterrence. Eng. Constr. Archit. Manag. 2019, 26, 245-266. [CrossRef]

41. Abad, I.; Cerrada, C.; Cerrada, J.A.; Heradio, R.; Valero, E. Managing RFID Sensors Networks with a General Purpose RFID Middleware. Sensors 2012, 12, 7719-7737. [CrossRef] [PubMed]

42. Aghenta, L.O.; Iqbal, M.T. Low-Cost, Open Source IoT-Based SCADA System Design Using Thinger.IO and ESP32 Thing. Electronics 2019, 8, 822. [CrossRef]

43. Wang, C.; Chen, X.; Soliman, A.-H.A.; Zhu, Z. RFID Based Manufacturing Process of Cloud MES. Future Internet 2018, 10, 104. [CrossRef]

44. Rojko, A. Industry 4.0 Concept: Background and Overview. Int. J. Interact. Mob. Technol. IJIM 2017, 11, 77-90. [CrossRef]

45. Aruväli, T.; Maass, W.; Otto, T. Digital Object Memory Based Monitoring Solutions in Manufacturing Processes. Procedia Eng. 2014, 69, 449-458. [CrossRef]

46. Unger, H.; Börner, F.; Müller, E. Context Related Information Provision in Industry 4.0 Environments. Procedia Manuf. 2017, 11, 796-805. [CrossRef]

47. Haddara, M.; Elragal, A. The Readiness of ERP Systems for the Factory of the Future. Procedia Comput. Sci. 2015, 64, 721-728. [CrossRef]

48. Schlank, R. Dynamic Memory: A Theory of Reminding and Learning in Computers and People; Cambridge University Press: Cambridge, UK, 1982.

49. Wen, J.; Li, S.; Lin, Z.; Hu, Y.; Huang, C. Systematic literature review of machine learning based software development effort estimation models. Inf. Softw. Technol. 2012, 54, 41-59. [CrossRef]

50. Shekapure, S.; Patil, D.D. Enhanced e-Learning Experience using Case based Reasoning Methodology. Int. J. Adv. Comput. Sci. Appl. 2019, 10, 236-241. [CrossRef]

51. Lajnef, T.; Chaibi, S.; Ruby, P.; Aguera, P.-E.; Eichenlaub, J.-B.; Samet, M.; Kachouri, A.; Jerbi, K. Learning machines and sleeping brains: Automatic sleep stage classification using decision-tree multi-class support vector machines. J. Neurosci. Methods 2015, 250, 94-105. [CrossRef]

52. Sun, X.; Chen, C.; Wang, L.; Kang, H.; Shen, Y.; Chen, Q. Hybrid Optimization Algorithm for Bayesian Network Structure Learning. Information 2019, 10, 294. [CrossRef]

53. Zeng, W.Z.; Zhang, D.Y.; Fang, Y.H.; Wu, J.W.; Huang, J.S. Comparison of partial least square regression, support vector machine, and deep-learning techniques for estimating soil salinity from hyperspectral data. $J$. Appl. Remote Sens. 2018, 12, 022204. [CrossRef]

54. Yu, J.; Sun, W.; Huang, H.; Wang, W.; Wang, Y.; Hu, Y. Crack Sensitivity Control of Nickel-Based Laser Coating Based on Genetic Algorithm and Neural Network. Coatings 2019, 9, 728. [CrossRef]

55. López, R.; González Gurrola, L.; Trujillo, L.; Prieto, O.; Ramírez, G.; Posada, A.; Juárez-Smith, P.; Méndez, L. How Am I Driving? Using Genetic Programming to Generate Scoring Functions for Urban Driving Behavior. Math. Comput. Appl. 2018, 23, 19. [CrossRef]

56. Álvarez-Díaz, M.; González-Gómez, M.; Otero-Giráldez, M. Forecasting International Tourism Demand Using a Non-Linear Autoregressive Neural Network and Genetic Programming. Forecasting 2018, 1, 90-106. [CrossRef] 
57. Guettiche, A.; Guéguen, P.; Mimoune, M. Seismic vulnerability assessment using association rule learning: Application to the city of Constantine, Algeria. Nat. Hazards 2017, 86, 1223-1245. [CrossRef]

58. Thabtah, F.; Qabajeh, I.; Chiclana, F. Constrained dynamic rule induction learning. Expert Syst. Appl. 2016, 63, 74-85. [CrossRef]

59. Sahu, B.K.; Pati, S.; Mohanty, P.K.; Panda, S. Teaching-learning based optimization algorithm based fuzzy-PID controller for automatic generation control of multi-area power system. Appl. Soft Comput. 2015, 27, 240-249. [CrossRef]

60. Celaschi, F. Advanced design-driven approaches for an Industry 4.0 framework: The human-centred dimension of the digital industrial revolution. Strateg. Des. Res. J. 2017, 10, 97-104. [CrossRef]

61. Guizzo, E.; Ackerman, E. The rise of the robot worker. IEEE Spectr. 2012, 49, 34-41. [CrossRef]

62. QB Robotics. Saphari-Safe and Autonomous Physical Human-Aware Robot Interaction. Available online: https://qbrobotics.com/projects/saphari-safe-autonomous-physical-human-aware-robot-interaction/ (accessed on 8 November 2019).

63. Koch, P.J.; van Amstel, M.K.; Dębska, P.; Thormann, M.A.; Tetzlaff, A.J.; Bøgh, S.; Chrysostomou, D. A Skill-based Robot Co-worker for Industrial Maintenance Tasks. Procedia Manuf. 2017, 11, 83-90. [CrossRef]

64. Kamarul Bahrin, M.A.; Othman, M.F.; Nor Azli, N.H.; Talib, M.F. Industry 4.0: A review on industrial automation and robotic. J. Teknol. 2016, 78, 137-143. [CrossRef]

65. Arnaiz-González, Á.; Fernández-Valdivielso, A.; Bustillo, A.; López de Lacalle, L.N. Using artificial neural networks for the prediction of dimensional error on inclined surfaces manufactured by ball-end milling. Int. J. Adv. Manuf. Technol. 2016, 83, 847-859. [CrossRef]

66. Meng, Z.; Wu, Z.; Gray, J. A Collaboration-Oriented M2M Messaging Mechanism for the Collaborative Automation between Machines in Future Industrial Networks. Sensors 2017, 17, 2694. [CrossRef]

67. Chen, M. Machine-to-Machine Communications: Architectures, Standards and Applications. KSII Trans. Internet Inf. Syst. 2012. [CrossRef]

68. Ali, A.; Shah, G.A.; Arshad, J. Energy Efficient Resource Allocation for M2M Devices in 5G. Sensors 2019, 19, 1830. [CrossRef]

69. Jacob Taquet, E.; Astorga, J.; Uncilla Galan, J.J.; Huarte, M.; Garcia Conejo, D.; Lopez De La Calle Marcaide, L.N. Hacia una ingraestructura de fabricación flexible, conectada e integrable en redes 5G. DYNA Ing. E Ind. 2018, 93, 656-662.

70. Seo, D.; Jeon, Y.-B.; Lee, S.-H.; Lee, K.-H. Cloud computing for ubiquitous computing on M2M and IoT environment mobile application. Clust. Comput. 2016, 19, 1001-1013. [CrossRef]

71. Pilloni, V. How Data Will Transform Industrial Processes: Crowdsensing, Crowdsourcing and Big Data as Pillars of Industry 4.0. Future Internet 2018, 10, 24. [CrossRef]

72. Veber, J. Management Inovací; Management Press: Prague, Czech Republic, 2016; ISBN 978-80-7261-423-3.

73. Burian, P. Internet Inteligentnich Aktivit; Grada: Praha, Czech Republic, 2014; ISBN 978-80-247-5137-5.

74. Cao, M.; Zhang, Q. Supply chain collaboration: Impact on collaborative advantage and firm performance. J. Oper. Manag. 2011, 29, 163-180. [CrossRef]

75. Liu, J.; Zhou, H.; Tian, G.; Liu, X.; Jing, X. Digital twin-based process reuse and evaluation approach for smart process planning. Int. J. Adv. Manuf. Technol. 2019, 100, 1619-1634. [CrossRef]

76. Shen, B.; Chan, H.-L. Forecast Information Sharing for Managing Supply Chains in the Big Data Era: Recent Development and Future Research. Asia Pac. J. Oper. Res. 2017, 34, 1740001. [CrossRef]

77. Choi, T.-M. Quick response in fashion supply chains with dual information updating. J. Ind. Manag. Optim. 2006, 2, 255-268. [CrossRef]

78. Du, T.C.; Lai, V.S.; Cheung, W.M.; Cui, X.L. Willingness to share information in a supply chain: A partnership-data-process perspective. Inf. Manag. 2012, 49, 89-98. [CrossRef]

79. Cachon, G.P.; Lariviere, M.A. Contracting to Assure Supply: How to Share Demand Forecasts in a Supply Chain. Manag. Sci. 2001, 47, 629-646. [CrossRef]

80. Croson, R.; Donohue, K. Imapct of pos data sharing on supply chain management: An experimental study. Prod. Oper. Manag. 2009, 12,1-11. [CrossRef]

81. Christopher, M.; Ryals, L.J. The Supply Chain Becomes the Demand Chain. J. Bus. Logist. 2014, 35, $29-35$. [CrossRef]

82. Juttner, U.; Christopher, M.; Baker, S. Demand chain management-integrating marketing and supply chain management. Ind. Mark. Manag. 2007, 36, 377-392. [CrossRef] 
83. Vezzetti, E. Product lifecycle data sharing and visualisation: Web-based approaches. Int. J. Adv. Manuf. Technol. 2009, 41, 613-630. [CrossRef]

84. Li, W.D.; Fuh, J.Y.H.; Wong, Y.S. An Internet-enabled integrated system for co-design and concurrent engineering. Comput. Ind. 2004, 55, 87-103. [CrossRef]

85. Zhao, F.L.; Tso, S.K.; Wu, P.S.Y. A cooperative agent modelling approach for process planning. Comput. Ind. 2000, 41, 83-97. [CrossRef]

86. Chen, Y.-M.; Liang, M.-W. Design and implementation of a collaborative engineering information system for allied concurrent engineering. Int. J. Comput. Integr. Manuf. 2000, 13, 11-30. [CrossRef]

87. Nikolakis, N.; Maratos, V.; Makris, S. A cyber physical system (CPS) approach for safe human-robot collaboration in a shared workplace. Robot. Comput. Integr. Manuf. 2019, 56, 233-243. [CrossRef]

88. Blossey, R. Self-cleaning surfaces-Virtual realities. Nat. Mater. 2003, 2, 301-306. [CrossRef]

89. Diemer, J. Sichere Industrie-4.0-Plattformen auf Basis von Community-Clouds. In Handbuch Industrie 4.0: Produktion, Automatisierung und Logistik; Vogel-Heuser, B., Bauernhansl, T., ten Hompel, M., Eds.; Springer: Berlin/Heidelberg, Germany, 2016; pp. 1-28. ISBN 978-3-662-45537-1.

90. Burdea, C.G.; Coiffet, P. Virtual Reality Technology; John Wiley \& Sons: New York, NY, USA, 2003.

91. Steuer, J. Defining virtual reality—dimensions determining telepresence. J. Commun. 1992, 42, 73-93. [CrossRef]

92. Crocetta, T.B.; de Araujo, L.V.; Guarnieri, R.; Massetti, T.; Ferreira, F.; de Abreu, L.C.; Monteiro, C.B.D. Virtual reality software package for implementing motor learning and rehabilitation experiments. Virtual Real. 2018, 22, 199-209. [CrossRef]

93. Yin, X.; Fan, X.; Yang, X.; Qiu, S.; Zhang, Z. An Automatic Marker-Object Offset Calibration Method for Precise 3D Augmented Reality Registration in Industrial Applications. Appl. Sci. 2019, 9, 4464. [CrossRef]

94. Jurášková, O. Velký Slovník Marketingových Komunikací; Grada Publishing Inc.: Prague, Czech Republic, 2012; ISBN 978-80-247-4354-7.

95. Soderberg, R.; Warmefjord, K.; Carlson, J.S.; Lindkvist, L. Toward a Digital Twin for real-time geometry assurance in individualized production. Cirp Ann. Manuf. Technol. 2017, 66, 137-140. [CrossRef]

96. Rosen, R.; von Wichert, G.; Lo, G.; Bettenhausen, K.D. About the Importance of Autonomy and Digital Twins for the Future of Manufacturing. IFAC Pap. OnLine 2015, 48, 567-572. [CrossRef]

97. El Saddik, A. Digital Twins the Convergence of Multimedia Technologies. IEEE Multimed. 2018, 25, 87-92. [CrossRef]

98. Batty, M. Digital twins. Environ. Plan. B Urban Anal. City Sci. 2018, 45, 817-819. [CrossRef]

99. Lutters, E. Pilot production environments driven by digital twins. S. Afr. J. Ind. Eng. 2018, $29,40-53$. [CrossRef]

100. Zhuang, C.; Liu, J.; Xiong, H. Digital twin-based smart production management and control framework for the complex product assembly shop-floor. Int. J. Adv. Manuf. Technol. 2018, 96, 1149-1163. [CrossRef]

101. Atorf, L.; Schorn, C.; Rossmann, J.; Schlette, C. A framework for simulation-based optimization demonstrated on reconfigurable robot workcells. In Proceedings of the 2017 IEEE International Systems Engineering Symposium (ISSE), Vienna, Austria, 11-13 October 2017; pp. 1-6.

102. Czech Statistical Office High-Tech Sektor. Available online: https://www.czso.cz/csu/czso/high_tech_sektor (accessed on 25 November 2019).

103. European Commission. Recommendation of 6 May 2003 Concerning the Definition of Micro, Small and Medium-Sized Enterprises; Text with EEA Relevance, Notified Under Document Number C (2003) 1422; European Commission: Brussels, Belgium, 2003.

104. Burt, C.; Burt, C.L. The Factors of the Mind: An Introduction to Factor-Analysis in Psychology; University of London Press: London, UK, 1940.

105. McDonald, R.P. Factor Analysis and Related Methods; Lawrence Erlbaum Associates: Hillsdale, NJ, USA, 1985; ISBN 978-0-89859-388-4.

106. Gorsuch, R.L. Factor Analysis, Classic ed.; Routledge: New York, NY, USA; Taylor \& Francis Group: London, UK, 2015; ISBN 978-1-138-83198-8.

107. Veza, I.; Mladineo, M.; Peko, I. Analysis of the current state of croatian manufacturing industry with regard to industry 4.0. In Proceedings of the 15th International Scientific Conference on Production Engineering CIM'2015: Computer Integrated Manufacturing and High Speed Machining, Vodice, Croatia, 10-13 June 2015; pp. 249-254. 
108. Frank, A.G.; Dalenogare, L.S.; Ayala, N.F. Industry 4.0 technologies: Implementation patterns in manufacturing companies. Int. J. Prod. Econ. 2019, 210, 15-26. [CrossRef]

109. Schumacher, A.; Erol, S.; Sihn, W. A Maturity Model for Assessing Industry 4.0 Readiness and Maturity of Manufacturing Enterprises. Procedia CIRP 2016, 52, 161-166. [CrossRef]

110. Pett, M.A.; Lackey, N.R.; Sullivan, J.J. Making Sense of Factor Analysis: The use of Factor Analysis for Instrument Development in Health Care Research; Sage Publications: Thousand Oaks, CA, USA, 2003; ISBN 978-0-7619-1949-0.

111. Hutcheson, G.; Sofroniou, N. The Multivariate Social Scientist: Introductory Statistics Using Generalized Linear Models; Sage Publications: London, UK; Thousand Oaks, CA, USA, 1999; ISBN 978-0-7619-5200-8.

112. Cohen, J. Statistical Power Analysis for the Behavioral Sciences, 2nd ed.; Lawrence Erlbaum Associates: Hillsdale, NJ, USA, 1988; ISBN 978-0-8058-0283-2.

113. Tabachnick, B.G.; Fidell, L.S.; Ullman, J.B. Using Multivariate Statistics, 7th ed.; Pearson: New York, NY, USA, 2019; ISBN 978-0-13-479054-1.

114. Samuels, P. Advice on Exploratory Factor Analysis; Birmingham City University: Birmingham, UK, 2016.

115. Řezanková, H.; Húsek, D.; Snášel, V. Shluková Analýza Dat; Professional Publishing: Prague, Czech Republic, 2009; ISBN 978-80-86946-81-8.

116. Rolinek, L.; Kopta, D.; Plevny, M.; Rost, M.; Kubecova, J.; Vrchota, J.; Marikova, M. Level of process management implementation in SMEs and some related implications. Transform. Bus. Econ. 2015, 14, 360-377.

117. Schulze, A. Industrie 4.0 steht noch ganz am Anfang. FLYACTS-Digit. Innov. Fact. 2014. Available online: https://www.flyacts.com/industrie-4-0-steht-noch-ganz-am-anfang (accessed on 25 November 2019).

118. Sastoque Pinilla, L.; Llorente Rodríguez, R.; Toledo Gandarias, N.; López de Lacalle, L.N.; Ramezani Farokhad, M. TRLs 5-7 Advanced Manufacturing Centres, Practical Model to Boost Technology Transfer in Manufacturing. Sustainability 2019, 11, 4890. [CrossRef]

119. Scremin, L.; Armellini, F.; Brun, A.; Solar-Pelletier, L.; Beaudry, C. Towards a framework for assessing the maturity of manufacturing companies in industry 4.0 adoption. In Analyzing the Impacts of Industry $4.0 \mathrm{in}$ Modern Business Environments; Hershey: Derry Township, PA, USA, 2018; pp. 224-254.

120. Oesterreich, T.D.; Teuteberg, F. Understanding the implications of digitisation and automation in the context of Industry 4.0: A triangulation approach and elements of a research agenda for the construction industry. Comput. Ind. 2016, 83, 121-139. [CrossRef]

121. Akdil, K.Y.; Ustundag, A.; Cevikcan, E. Maturity and Readiness Model for Industry 4.0 Strategy. In Industry 4.0: Managing the Digital Transformation; Ustundag, A., Cevikcan, E., Eds.; Springer International Publishing: Cham, Switzerland, 2018; pp. 61-94. ISBN 978-3-319-57870-5.

122. Gökalp, E.; Şener, U.; Eren, P.E. Development of an Assessment Model for Industry 4.0: Industry 4.0-MM. In Software Process Improvement and Capability Determination; Mas, A., Mesquida, A., O'Connor, R.V., Rout, T., Dorling, A., Eds.; Springer International Publishing: Cham, Switzerland, 2017; Volume 770, pp. 128-142. ISBN 978-3-319-67382-0.

123. Lee, J.; Jun, S.; Chang, T.-W.; Park, J. A Smartness Assessment Framework for Smart Factories Using Analytic Network Process. Sustainability 2017, 9, 794. [CrossRef]

124. Ślusarczyk, B. Industry 4.0-Are we ready? Pol. J. Manag. Stud. 2018, 17, 232-248. [CrossRef]

125. Stefan, L.; Thom, W.; Dominik, L.; Dieter, K.; Bernd, K. Concept for an evolutionary maturity based Industrie 4.0 migration model. Procedia CIRP 2018, 72, 404-409. [CrossRef]

126. Block, C.; Freith, S.; Kreggenfeld, N.; Morlock, F.; Prinz, C.; Kreimeier, D.; Kuhlenkötter, B. Industrie 4.0 als soziotechnisches Spannungsfeld: Ganzheitliche Betrachtung von Technik, Organisation und Personal. ZWF Z. Für Wirtsch. Fabr. 2015, 110, 657-660. [CrossRef]

127. Brunet-Thornton, R.; Martinez, F. (Eds.) Analyzing the Impacts of Industry 4.0 in Modern Business Environments; Advances in Business Information Systems and Analytics; IGI Global: Hershey, PA, USA, 2018; ISBN 978-1-5225-3468-6.

128. Durana, P.; Kral, P.; Stehel, V.; Lazaroiu, G.; Sroka, W. Quality Culture of Manufacturing Enterprises: A Possible Way to Adaptation to Industry 4.0. Soc. Sci. 2019, 8, 124. [CrossRef]

129. Giddens, A.; Sutton, P.W. Sociologie; Argo: Prague, Czech Republic, 2013; ISBN 978-80-257-0807-1.

130. Hair, J.F.; Money, A.H.; Samouel, P.; Page, M. Research Methods for Business. Educ. Train. 2007, 49, $336-337$. [CrossRef] 
131. Greener, S. Business Research Methods; Ventus Publishing: London, UK, 2008; ISBN 978-87-7681-421-2.

132. Roberts, F.S. The questionnaire method. In Structure of Decision: The Cognitive Maps of Political Elites; Princeton University Press: Princeton, NJ, USA, 2015; pp. 333-342.

133. Saunders, M.N.K.; Lewis, P.; Thornhill, A. Research Methods for Business Students, 5th ed.; Prentice Hall: New York, NY, USA, 2009; ISBN 978-0-273-71686-0. 